\title{
Investigation on the Synergetic Effects of Carbon Nanotube and Graphene Oxide on Carbon Fiber Reinforced Epoxy Prepreg Composites
}

\author{
Gözde Berkay ${ }^{1}$, Seçkin Erden² \\ ${ }^{1}$ Ege University / Graduate School of Natural and Applied Science / 35040, Izmir, Turkey \\ ${ }^{2}$ Ege University / Mechanical Engineering Department / 35040, Izmir, Turkey
}

Corresponding Author: Seçkin Erden, seckin.erden@gmail.com.

\begin{abstract}
Enhancement of electrical properties of carbon fiber reinforced (CFR) epoxy matrix composites was aimed by incorporating varying amounts $(0.5,1,2,4,7,10$, and $15 \mathrm{wt} \%$ - percentage by weight) of carbon nanoparticles (CNPs) into the resin [CNPs used were multi walled carbon nanotubes (MWCNTs) and graphene oxides (GOs)]. Besides, within these CNP percentages, MWCNT to GO composition ratio was also changed $(100: 0,80: 20,50: 50,20: 80$, and 0:100) in order to investigate the synergy between these two type of CNPs. Carbon fiber/epoxy composites were produced via prepregging technique, followed by compression molding method. The change in electrical conductivity of the composites was examined in three directions: Fiber direction, transverse direction, and through-thickness direction. Additionally, mechanical property investigation was carried out by determining the interlaminar shear strength (ILSS) of composites by conducting short beam shear tests (SBS). Scanning electron microscopy (SEM) and energy-dispersive x-ray spectroscopy (EDS) analyses were performed for morphology investigation and element characterization of the CNP surfaces. The results revealed up to 5.8 (for $15 \mathrm{wt} \%$ and 100:0), 217 (for $0.5 \mathrm{wt} \%$ and 100:0), and 34 (for $0.5 \mathrm{wt} \%$ and 20:80) fold increases in conductivity values in fiber, transverse, and thickness directions, respectively, when compared to that of the neat composite. For the thickness direction, the synergy between the NPs was obvious while some other high values were also achieved for other CNP compositions. Also, approximately $87 \%$ increase in ILSS value (for $0.5 \mathrm{wt} \%$ and 100:0) was achieved by CNP addition.
\end{abstract}

\section{ARTICLE HISTORY}

Received: 06.05.2020

Accepted: 10.06.2020

\section{KEYWORDS}

Carbon fiber epoxy prepreg composite, multi walled carbon nanotube, graphene oxide, electrical conductivity, mechanical property.

\section{INTRODUCTION}

Fiber reinforced polymer/plastic (FRP) is a composite material formed by heterogeneous mixing of two or more materials in order to achieve new properties. They are composed of fiber and matrix bound at the common interface of these both phases. Mechanical and physical properties of FRP depend on the properties of its constituents and some micro scale interactions [1]. Matrices, despite having low mechanical property values, affect many properties of the composite [2]. Although highperformance FRP composites offer many advantages such as high mechanical strength, dimensional and thermal stability, hardness, wear resistance, and low density properties, they lack conductivity when it comes to electrical properties as the resin material has only $1 \%$ conductivity compared to that of metals. But the reinforcement phase, besides load bearing and contributing to composite's rigidity, strength, thermal stability, and other structural or functional properties, can also make the composite electrically conductive or dielectric depending on the type of fiber material [3]. Therefore, reinforcement has been a good candidate to provide the required electrical conductivity or transmission characteristics. Reinforcement shape and fiber orientation with respect to the electric current direction is important.

Conductive composites with volumetric conductivity of more than $10^{-11} \mathrm{~S} / \mathrm{mm}$ have still importance in applications such as conductive adhesives, antistatic coatings and films, electromagnetic shielding materials for electronic devices, and thermal interface materials thanks to these conductive reinforcements. Carbon fiber (CF), which has become a widespread reinforcement especially in costly FRPs and has up to $95 \mathrm{wt} \%$ carbon atom content, can be a good choice of reinforcement as it has electrical conductivity of up to

To cite this article: Berkay G, Erden S. 2020. Investigation on the synergetic effects of carbon nanotube and graphene oxide on carbon fiber reinforced epoxy prepreg composites. Tekstil ve Konfeksiyon, 30(2), 144-154. 
$150 \mathrm{~S} / \mathrm{mm}[4,5]$. Cellulose CFs are not used in structural applications, but their low thermal conductivity makes them useful in insulation and guiding applications such as rocket nozzles, rocket tips, and heat shields [6, 7]. An expensive alternative can be graphite fibers, which have at least $99 \%$ carbon atom content and 10 folds of electrical conductivity compared to that of CFs $[2,5]$. Other options are the use of fillers such as microparticles of metals, carbon (known as carbon black (CB)), and graphite to achieve conductive polymers.

After the developments in nanotechnology, nano sized structures, which are generally named as nanofillers, have also been an alternative choice, recently. These are classified as nanocrystals, nanoparticles (NPs), nanotubes, nanowires, nanorods or nano thin films. The main reason of interest on these materials is that the items exhibit unusual properties and functionality different from their bulk structures in a certain size range [8,9]. NPs, defined as particles having a dimension of $100 \mathrm{~nm}$ or less, constitute the fundamentals of nanosized materials [9, 10]. Most known reasons making them attractive are quantum size effects, dimension dependent electronic structure, unique characters of surface atoms, and high surface/volume ratio. Their extraordinary properties paved the way for products such as high activity catalysts, special optical materials, superconductors, abrasion resistant additives, surface active materials, drug carriers, special diagnosis devices, nanocarriers, sensors, nanomachines, and high density data storage cells $[8,11]$. Today, metal, metal alloy, ceramic, and polymer-based nanoparticles or their mixtures can be prepared with different morphologies such as core-shell, doped, sandwich, cavity, spherical, rod-like and multifaceted [11]. In use as polymer filler, large surface area causes strong polymer/filler interaction and enables more efficient reinforcement at lower loads. This provides improved material performance and helps reduce costs by allowing less material usage [12]. These developments led to the use of CNPs widely, making them popular subject of studies, recently. CNPs, which are known as allotropes of carbon atom, are CNTs, graphite, graphene $(\mathrm{G})$, and fullerene [13]. Among these, CNTs, being the first thoroughly focused type, have various applications such as data storage devices, capacitors, flat panel screens, heat exchangers, high-strength composites, filter membranes, space suits, biosensors, fuel cells, lab-on-a-chip devices, etc [14].

Percolation threshold is explained as the amount of critical reinforcement material at which there is a sudden increase in the value of electrical conductivity during the formation of a continuous electron direction or a conductive network. In the range of values above the percolation threshold, it was observed that the conductivity values of the composite material reaches a saturation point as multiple electron directions occur within the matrix. Above mentioned microfillers and CFs can help reach the percolation threshold, but at an incorporation amount of 10-50 wt \%, which causes decrease in composite mechanical properties and increase in its weight. At this point, addition of CNT and $\mathrm{G}$ at a low fraction comes up as a solution, which provides increase in composite conductivity owing to the high length/width ratios and individual conductivity values of these NPs. Less than $5 \mathrm{wt} \%$ CNT inclusion helps pass the percolation threshold and provide the adequate conductivity value for most polymers. Although there is not a specific value for CNT/epoxy nanocomposite studies, a range of $0.002-7 \mathrm{wt} \%$ can be seen in previous results depending on the production technique and type of CNTs. Also, it was stated that composites with homogeneously dispersed CNTs have 50 folds conductivity value than that of composites with aggregated CNTs. Therefore, to determine the percolation threshold for NP incorporated polymer matrix composites (PMCs), it is essential to pay attention to width/length ratio, prevent NP aggregation at nano scale, and assure homogeneous dispersion within the matrix at micro scale [15].

Not much work has been done on NP incorporated CFR epoxy composites yet. An example is the one by Lonjon et al. [16], in which $0.4 \mathrm{wt} \%$ double walled carbon nanotubes (DWCNT) was added into CF/epoxy. Here, electrical conductivity value in thickness direction was found as 2.17 x $10^{-4} \mathrm{~S} / \mathrm{mm}$. Sawi et al. [17] also studied the inclusion of $0.4 \mathrm{wt} \%$ DWCNT where the conductivities changed from $15 \times 10^{-6}$ to $108 \times 10^{-6} \mathrm{~S} / \mathrm{mm}, 7 \times 10^{-4}$ to $18 \times 10^{-4} \mathrm{~S} / \mathrm{mm}$, and 6.2 to $6.3 \mathrm{~S} / \mathrm{mm}$ for thickness, transverse, and fiber directions, respectively when compared to neat composites. They also determined the conductivity of epoxy/DWCNT nanocomposites in thickness direction as $10^{-4} \mathrm{~S} / \mathrm{mm}$. An investigation on continuous production of $3 \mathrm{wt} \% \mathrm{G}$ solution coated $\mathrm{CF} /$ epoxy prepreg composites yielded an increase in conductivity for thickness direction from $2 \times 10^{-3}$ to $7 \times 10^{-3}$ $\mathrm{S} / \mathrm{mm}$ and $90^{\circ}$ flexural strength, $0^{\circ}$ flexural strength, and ILSS values also increased [18]. Another study with $\mathrm{CF} /$ epoxy composites involves incorporation of $1 \mathrm{wt} \% \mathrm{G}$ into epoxy. Through-thickness electrical conductivity, transverse thermal conductivity, and mechanical properties (compression, in-plane shear, mode I, and mode II) were investigated. Electrical conductivity increased from $5.6 \times 10^{-7}$ to $13.1 \times 10^{-7} \mathrm{~S} / \mathrm{mm}$. This low increase compared to the case of nanocomposites without fibers was explained as the effect of CFs at about $55 \mathrm{vol} . \%$, which have high conductivity range [19]. Another work on $0.1 \mathrm{wt} \% \mathrm{GO}$ incorporated CF/epoxy prepreg composites, which were compatible for series production, yielded increases in flexural strength, longitudinal and transverse tensile strength, and ILSS values [20]. A study on $0.5 \mathrm{wt} \%$ MWCNTs incorporated CFR epoxy composites revealed the importance of alignment of fiber and its effects on ILSS properties [21]. On the other hand, synergetic effect of hybrid nanofillers was rarely studied in CFR epoxy composites. One example is the work of Wang et al. [22], who investigated addition of MWCNT\&G NPs at $1 \mathrm{wt} \%$. They varied CNT:G ratio as 10:0, 9:1, 7:3, 5:5, 3:7, 1:9, and $0: 10$. Flexural and tensile strength values decreased for $G$ case, but increased for CNT case when compared to neat composite. Also, some hybrid NP ratios were high as well. Flexural modulus increased for all NP levels. They then kept 1:9 hybrid NP ratio constant and changed the NP 
amount as $0.5,1.0$, and $1.5 \mathrm{wt} \%$. Flexural strength, flexural modulus, and ILSS increased all with a decrease in flexural strength and ILSS for $1.5 \mathrm{wt} \%$. They proposed that the added CNTs entangled the Gs, filled gaps between Gs, and restricted crack growth in the resin. Another work utilized the inclusion of MWCNTs and Gs into CFR epoxy composites at $0.5 \mathrm{wt} \%$ by applying the NPs through sizing process and the composite production via prepregging. G:MWCNT ratio was kept as 1:4. Flexural and tensile strength, and ILSS increased more in case of hybrid nanofiller addition. They attributed this to higher interfacial adhesion as less holes were present and more matrix was attached on the pullout CF surfaces. Better surface wettability and roughness of $\mathrm{CFs}$ indicating higher interaction area between $\mathrm{CF}$ and epoxy matrix, and also reduced stress concentration was stated to occur [28].

Researches on the synergy between different CNPs incorporated into epoxy resin without CFs were also carried out recently in order to improve the epoxy nanocomposite properties. Han et al. [23] investigated MWCNT and G addition effects on mechanical and electrical properties of epoxy. Lap shear strength, Young's modulus, tensile strength, toughness all improved more with up to 0.5 volumetric percentage (vol\%) of MWCNT\&G hybrid nanofillers, which also showed better colloidal dispersion state than the alone types of both. Percolation threshold decreased with MWCNT\&G, and electrical conductivity raised from $10^{-15}$ to $10^{-6} \mathrm{~S} / \mathrm{mm}$, which was studied for up to $2 \mathrm{vol} \% \mathrm{NP}$ addition. In another study, MWCNT and G was added into epoxy at only $0.1 \mathrm{wt} \%$ for flexural strength and modulus investigation, and up to $4 \mathrm{wt} \%$ for electrical property analyses. They also changed MWCNT:G ratio as 10:0, 8:2, 6:4, 4:6, 2:8, and $0: 10$. Mechanical values increased for $8: 2$ ratio, but decreased linearly for other ratios from MWCNT to G filler. Electrical conductivity raised from $10^{-15}$ to $10^{-6} \mathrm{~S} / \mathrm{mm}$ for 4 wt $\%$ MWCNT and hybrid NP addition, and to $10^{-8} \mathrm{~S} / \mathrm{mm}$ for $\mathrm{G}$ incorporation. Percolation threshold was in the order hybrid $\mathrm{NP}<\mathrm{CNT}<\mathrm{G}$, but viscosity was vice versa. Colloidal dispersion seemed better for $\mathrm{G}$ case [24]. Ghaleb et al. [25] studied up to 1 vol\% MWCNT or G inclusion into epoxy and found decrease in tensile strength and Young's modulus compared to that of neat epoxy except for $1 \%$ MWCNT case, which was only equal to the neat value. They also investigated hybrid NP fillers for $0.5 \mathrm{vol} \%$ in which tensile strength and modulus passed the neat values for the case G:MWCNT $=0.1: 0.4$. Electrical conductivity raised from $10^{-9}$ to $10^{-6} \mathrm{~S} / \mathrm{mm}$ for MWCNT, $10^{-5}$ for $\mathrm{G}$, and $10^{-3}$ for MWCNT\&G. They proposed that CNTs were aligned on G surfaces, forming a network. Another study involving additions of various combinations of $\mathrm{G}$, single walled carbon nanotubes (SWCNTs) as well as MWCNTs into epoxy, focused on mechanical properties such as Young's modulus, tensile strength, and fatigue of epoxy. Contrary to Ghaleb et $a l$, , they stated that MWCNT\&G combination resulted in more improved properties as Gs aggregated along CNT chains and formed a network structure [26]. Mechanical properties such as Young's modulus, tensile strength, elongation at break, fracture toughness were further studied in MWCNT and GO added epoxy. Increase in all values were recorded according to neat resin with the incorporation of NPs at $1 \mathrm{wt} \%$. Hybrid nanofillers had much positive effect, which was explained as GOs deflected the cracks and helped more bridging by MWCNTs [27].

Based on the above-summarized literature, this work focusses on investigating the synergy between CNTs and Gs incorporated into CFR epoxy composites. Carbon fiber/epoxy composites with NP inclusion were produced by prepregging, which is a technique compatible to continuous production. The composites were characterized in means of mechanical and electrical properties. Conductivities were measured in fiber, transverse, and through-thickness directions. ILSS of composites were determined. SEM and EDS analyses were performed. Therefore, it became possible to contribute to fill some lack in the topic of hybrid nanofiller incorporated $\mathrm{CF} /$ epoxy composites. This was realized by varying the CNP amount added into epoxy as $0.5,1,2,4,7$, 10, and $15 \mathrm{wt} \%$, and CNT:GO composition ratio was also changed as 100:0, 80:20, 50:50, 20:80, and 0:100. So, 35 different NP incorporated specimens were investigated besides the neat CFR epoxy composites.

\section{MATERIAL AND METHOD}

\subsection{Material}

CFs (A-42; sized, $\rho=1.76 \mathrm{~g} / \mathrm{cm}^{3}$ ) were kindly supplied by DowAksa. Epoxy resin (Araldite LY 1564 SP; $\rho=1.2$ $\mathrm{g} / \mathrm{cm}^{3}$ ) and hardener (Aradur 3486; $\rho=0.94 \mathrm{~g} / \mathrm{cm}^{3}$ ) were purchased from Huntsman. MWCNT powder was Baytubes C $150 \mathrm{P}$ (outer $\mathrm{d}=13 \mathrm{~nm}$, inner $\mathrm{d}=4 \mathrm{~nm}$, length $>1 \mu \mathrm{m}$, $\rho=120 \mathrm{~kg} / \mathrm{m}^{3}$ ). Graphene nano powder (AO-2; thickness $<3$ $\mathrm{nm}, 3-8$ layers, dimensions 2-8 microns) was supplied from Graphene Supermarket. Sulfuric acid $\left(\mathrm{H}_{2} \mathrm{SO}_{4}\right)$, nitric acid $\left(\mathrm{HNO}_{3}\right)$, ethanol $\left(\mathrm{C}_{2} \mathrm{H}_{6} \mathrm{O}\right)$, and acetone $\left(\mathrm{C}_{3} \mathrm{H}_{6} \mathrm{O}\right)$ used in $\mathrm{GO}$ synthesis were purchased from Sigma Aldrich.

\subsection{Method}

Before composite production, epoxy matrix was modified via NP incorporation. This was done by addition of MWCNTs and GOs into epoxy at varying fractions. NP amount included in the matrix and composition of each of these NP amounts are given in Table 1. Therefore, 35 different NP incorporated composite specimens were produced besides the neat carbon fiber/epoxy. Before that, graphene NPs were subjected to oxidation in order to produce GOs.

\subsubsection{Procedure for graphene oxidation}

Graphene was oxidized chemically, which was a technique used for oxidation of CNTs [29]. This way it is possible to functionalize $\mathrm{G}$ surfaces by creating carboxylic acid groups on them. So, required amount of graphene was added into $200 \mathrm{ml}$ of ethanol, and mixed at $60^{\circ} \mathrm{C}$ for $2 \mathrm{hrs}$ using a magnetic stirrer Afterwards, G+ethanol mixture was kept in an ultrasonic bath until the ethanol evaporated (Figure 1). This was done to exfoliate the $G$ layers and to prevent their aggregation and precipitation. 
Table 1. Notation of produced composites

\begin{tabular}{ccc|ccc}
\hline Code & $\begin{array}{c}\text { NP } \\
\text { amount } \\
\text { (wt\%) }\end{array}$ & $\begin{array}{c}\text { NP } \\
\text { composition } \\
\text { (CNT:GO) }\end{array}$ & Code & $\begin{array}{c}\text { NP } \\
\text { amount } \\
\text { (wt\%) }\end{array}$ & $\begin{array}{c}\text { NP } \\
\text { composition } \\
\text { (CNT:GO) }\end{array}$ \\
\hline $0.5-100: 0$ & & $0: 100$ & $7-100: 0$ & & $0: 100$ \\
$0.5-80: 20$ & & $80: 20$ & $7-80: 20$ & & $80: 20$ \\
$0.5-50: 50$ & 0.5 & $50: 50$ & $7-50: 50$ & 7 & $50: 50$ \\
$0.5-20: 80$ & & $20: 80$ & $7-20: 80$ & & $20: 80$ \\
$0.5-0: 100$ & & $0: 100$ & $7-0: 100$ & & $0: 100$ \\
\hline $1-100: 0$ & & $0: 100$ & $10-100: 0$ & & $0: 100$ \\
$1-80: 20$ & & $80: 20$ & $10-80: 20$ & & $80: 20$ \\
$1-50: 50$ & 1 & $50: 50$ & $10-50: 50$ & 10 & $50: 50$ \\
$1-20: 80$ & & $20: 80$ & $10-20: 80$ & & $20: 80$ \\
$1-0: 100$ & & $0: 100$ & $10-0: 100$ & & $0: 100$ \\
\hline $2-100: 0$ & & $0: 100$ & $15-100: 0$ & & $0: 100$ \\
$2-80: 20$ & & $80: 20$ & $15-80: 20$ & & $80: 20$ \\
$2-50: 50$ & 2 & $50: 50$ & $15-50: 50$ & 15 & $50: 50$ \\
$2-20: 80$ & & $20: 80$ & $15-20: 80$ & & $20: 80$ \\
$2-0: 100$ & & $0: 100$ & $15-0: 100$ & & $0: 100$ \\
\hline $4-100: 0$ & & $0: 100$ & & & \\
$4-80: 20$ & & $80: 20$ & & & \\
$4-50: 50$ & 4 & $50: 50$ & & & \\
$4-20: 80$ & & $20: 80$ & & & \\
$4-0: 100$ & & $0: 100$ & & & \\
\hline
\end{tabular}

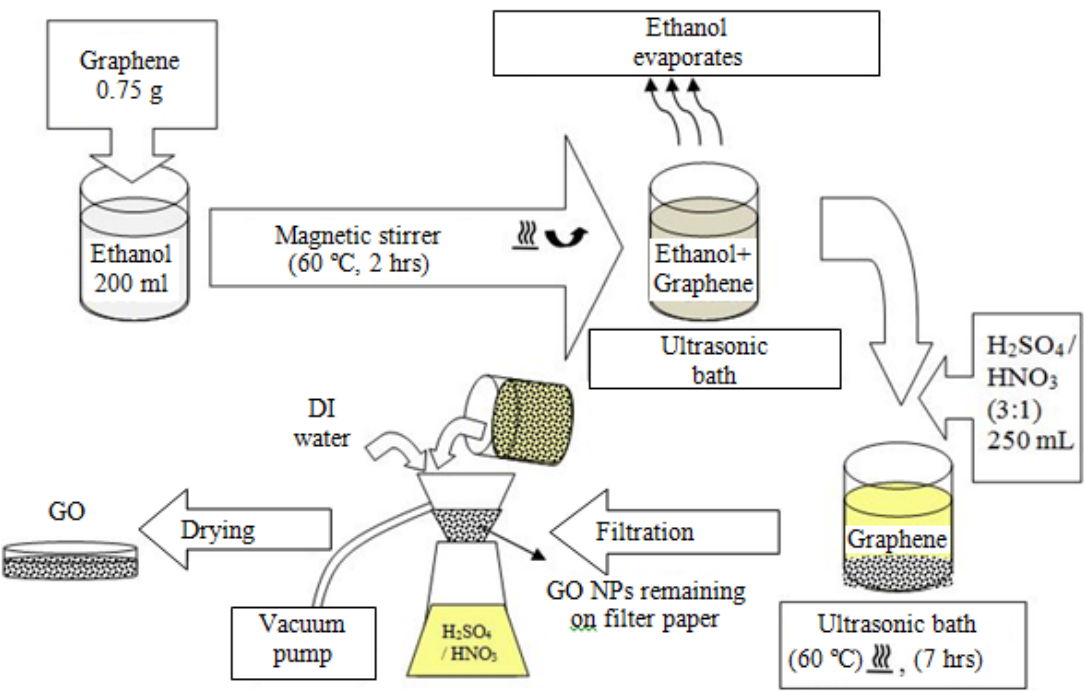

Figure 1. Graphene oxidation process scheme

Next, $250 \mathrm{ml}$ of $\mathrm{H}_{2} \mathrm{SO}_{4} / \mathrm{HNO}_{3}$ mixture (3:1 ratio) was added into the $\mathrm{G}$ beaker, which was kept in ultrasonic bath at $60^{\circ} \mathrm{C}$ for $7 \mathrm{hrs}$ and then left to cool down to room temperature. The solution was then diluted by deionized (DI) water and filtered using a vacuum filtration apparatus. This was repeated a few times and GOs gathered on filter papers were dried at $70^{\circ} \mathrm{C}$ using an oven, which were finally pounded and ground in a mortar.

\subsubsection{Composite production}

NP incorporated CFR epoxy composites were manufactured as illustrated in Figure 2. First, epoxy matrix was modified by incorporation of NPs. Then CF/epoxy prepregs were produced using this nano-epoxy resin system. Finally, these prepregs were consolidated into laminated carbon fiber/epoxy composites by hot pressing technique.

When the specimen dimensions for electrical and mechanical tests (Electrical: $20 \times 20 \times 1 \mathrm{~mm}$; ILLS: 10 × 20 $\mathrm{x} 1 \mathrm{~mm}$ ) are considered, it was approximated that $1 \mathrm{~m}$ length of $\mathrm{CF}$ would be adequate for production of two prepreg layers. This was realized by carefully wrapping this fiber onto a $20 \times 150 \times 1 \mathrm{~mm}$ galvanized steel plate, already involving $20 \mathrm{~mm} \times 100 \mathrm{~mm}$ surface area on both sides. The 
plates were coated with PTFE (Teflon) films for easy release of prepreg layers. $1 \mathrm{~m}$ length of $\mathrm{CF}$ was weighed as $0.858 \mathrm{~g}$, which was used to calculate $\mathrm{V}_{\text {fiber }}$ in Equation 1 where fiber volume fraction $\left(v_{f}\right)$ was considered as $60 \%$. Required volume of epoxy resin system (resin+hardener) was calculated from this equation, which then made it possible to find the required matrix weight.

Epoxy: Hardener ratio of the resin system was taken as 100:34 parts by weight, which was specified in manufacturer's material data sheet. This way, amount of required hardener was also calculated.

Amounts of NPs to be added into matrix at 0.5, 1, 2, 4, 7, 10 , and $15 \mathrm{wt} \%$ and amounts of MWCNTs and GOs of each NP composition (100:0, 80:20, 50:50, 20:80, 0:100) were calculated using Equation 2:

The matrix was modified by incorporation of above calculated amounts of MWCNTs and GOs into epoxy resin as shown in Figure 3.

Required amounts of NPs were added into acetone and this suspension was mixed with epoxy resin using an ultrasonic homogenizer (Hielscher UP400S) operated at 50\% amplitude for $10 \mathrm{~min}$ inside an ice bath to prevent heating of epoxy. G+acetone+epoxy mixture was then kept at $80^{\circ} \mathrm{C}$ for $1 \mathrm{hr}$ inside a vacuum oven, so as to evaporate the acetone and obtain the nano-epoxy resin.

Epoxy resin system to be used for prepregging was obtained by mechanically mixing the above obtained nanoepoxy resin and the hardener at the ratio 100:34. CFs wrapped onto steel plate molds were wetted thoroughly and evenly by required amount of modified epoxy resin system. The molds were then kept inside an oven at $80^{\circ} \mathrm{C}$ for 30 min to realize the gelation process of epoxy resin system as given in manufacturer's material data sheet. As prepared $\mathrm{CF} /$ nano-epoxy prepregs were then taken out of oven and kept in a freezer until use for laminate production.

CF/nano-epoxy composite laminates were produced afterwards by placing 8 layers of prepreg sheets in a steel mold with $20 \times 100 \mathrm{~mm}$ dimensions and curing them at $120^{\circ} \mathrm{C}$ for $2 \mathrm{hrs}$ under 1 ton (50 bars) using a hot press. $\mathrm{CF} /$ nano-epoxy composite laminates produced this way were left to cool down to room temperature. As a result, 35 different NP incorporated composites were manufactured besides the neat CFR epoxy composite.

$$
\begin{aligned}
& v_{\mathrm{f}}=\frac{\mathrm{V}_{\text {fiber }}}{\mathrm{V}_{\text {fiber }+ \text { matrix }}}=\frac{m_{\text {fiber }} / \rho_{\text {fiber }}}{m_{\text {composite }} / \rho_{\text {composite }}} \\
& m_{\mathrm{NP}}=m_{\text {resin }} \times \text { NP\% x NP distributi on } \%
\end{aligned}
$$

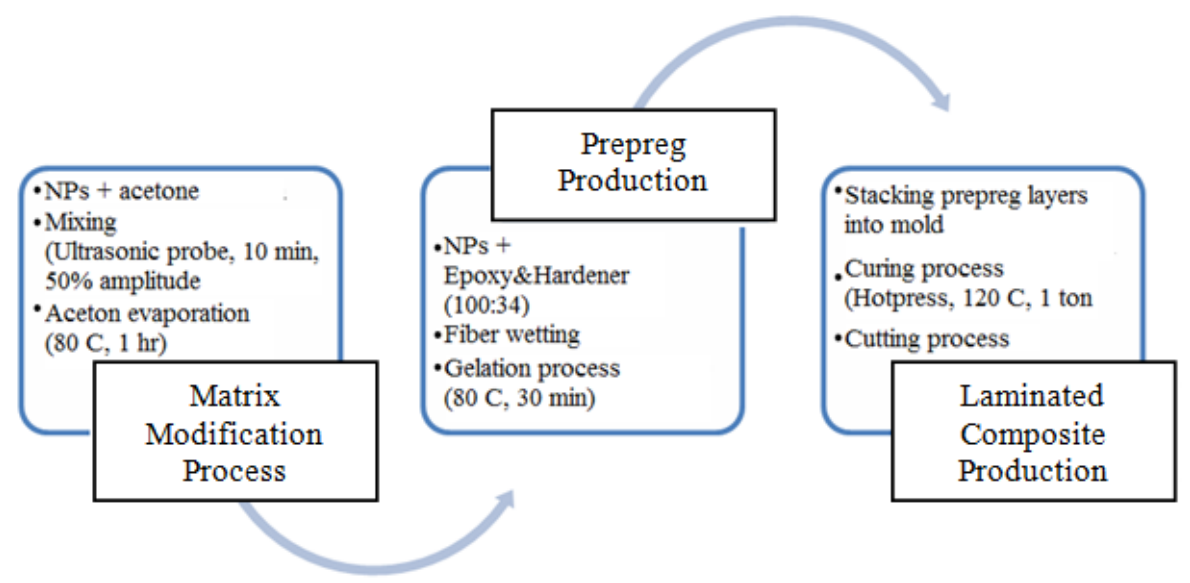

Figure 2. CF/epoxy composite production flowchart

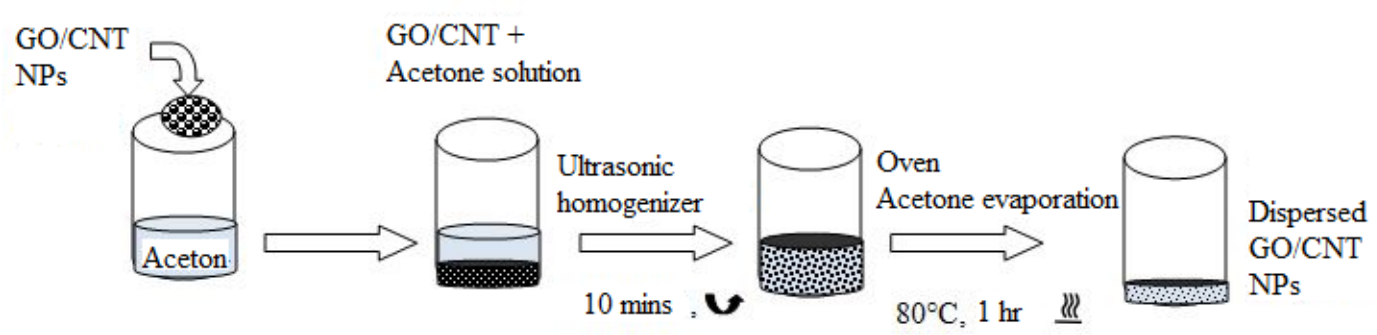

Figure 3. Matrix modification procedure 


\subsection{Characterization}

\subsubsection{Electrical conductivity test}

Composite specimens were cut into pieces of 20 x $20 \mathrm{~mm}$ using a band saw. AC electrical conductivities were determined in the fiber, transverse, and through-thickness directions of composites as shown in Figure 4(a) by using the experimental setup given in Figure 4(b).

A benchtop LCR Meter (Gw INSTEK LCR-821 340) was used for electrical conductivity determination. A frequency of $10 \mathrm{kHz}$ and a voltage of $1 \mathrm{~V}$ was applied. 5 specimens were tested for each composite type. Copper plates were glued on the relevant opposite surfaces of specimens. The resistance $(R)$ value was read for each specimen in three different directions. Equation 3 was used to calculate the electrical conductivity:

$\frac{1}{R}=\frac{\sigma \times \mathrm{A}}{l}$

where $R$ is the resistance $(\Omega), \sigma$ is the electrical conductivity (Siemens/mm), A is the surface area, and $l$ is the distance between the relevant opposite surfaces.

\subsubsection{Short beam shear (SBS) test}

The specimens were cut into pieces of 10 x $20 \mathrm{~mm}$ dimensions using a band saw [30]. SBS tests were conducted according to ASTM D2344 and DIN 29971 standards in order to determine the ILSS values for each type of composite. A specific three-point bending test apparatus was used for the tests. Diameters of the loading pin and the two support pins were $6 \mathrm{~mm}$ each. The tests were realized by using a Shimadzu AUTOGRAPH AG - IS universal testing machine equipped with $5 \mathrm{kN}$ load cell. Crosshead speed was kept as $1 \mathrm{~mm} / \mathrm{min}$. At least 3 specimens were tested for each composite type. ILSS values were calculated using Equation 4:

$\tau=0.75 \times \frac{F_{\max }}{b x t}$

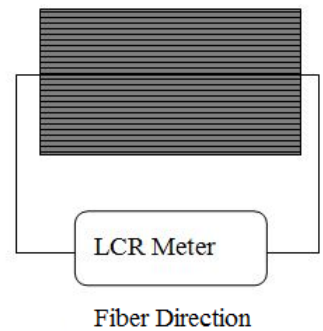

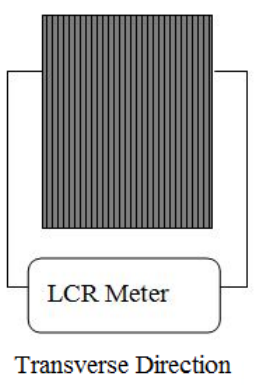

(a) where $\tau$ is ILSS $\left(\mathrm{N} / \mathrm{mm}^{2}=\mathrm{MPa}\right), F_{\max }$ is maximum force $(\mathrm{N}), b$ is specimen width $(\mathrm{mm})$, and $t$ is specimen thickness $(\mathrm{mm})$.

\subsubsection{SEM-EDS Analysis}

SEM-EDS analyses were performed for morphology investigation and element characterization of the MWCNT and GO NPs. Also, the dispersion state of these hybrid nanofillers were examined. Thermoscientific Apreo $\mathrm{S}$ at Ege University Central Research Testing and Analysis Laboratory was used for SEM-EDS analyses.

\section{RESULTS AND DISCUSSION}

\subsection{Electrical conductivity of composites}

Electrical conductivity values in fiber, transverse, and thickness directions with respect to NP amount and NP compositions are given in Figure 5 where the graphs are plotted in logarithmic scale. Most of the composites show a sudden increase at about $0.5 \mathrm{wt} \%$ especially for CNT dominant cases and between 0.5-1 wt $\%$ for GO dominant cases. These correspond to other findings that refer to the percolation thresholds of NP incorporated CF/epoxy composites $[15,23]$. Much higher conductivity values were recorded in fiber direction when compared to those in transverse and thickness directions. And also, much more increase was achieved in the transverse direction when compared to that of the neat composites. These two findings, both occurring in case of 100:0 composites, indicate that $\mathrm{CFs}$ dominate the electron flow in fiber direction and MWCNTs interact well with CFs to develop conductive paths both in fiber and transverse directions. Besides, when all the conductivity curves are examined, it can be noticed that the values in all three directions are generally lower for 0:100 composites than those of the other four NP compositions. This can be due to the change in contact geometry caused by CNT-GO interaction from 0$\mathrm{D}$ (dimensional) point geometry to 1-D linear geometry, thereby reducing the electrical resistance along the NP compositions involving MWCNT [23, 31].
(4)
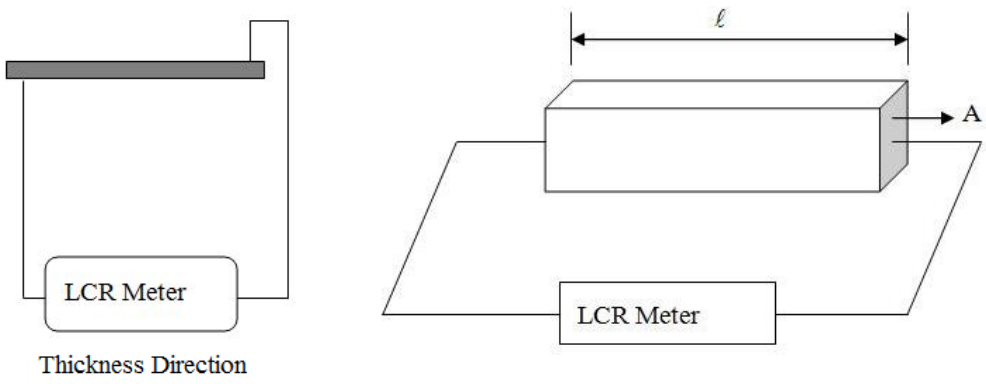

(b)

Figure 4. (a) Conductivity measurement directions of composites, (b) Experimental setup for conductivity measurement 
When the graphs are examined in detail, it is obvious for $100 \% \mathrm{CNT}$ and $100 \%$ GO specimens that the sudden increase in fiber direction almost hits the bottom at $1 \mathrm{wt} \%$ (Figure 5 (a and e). This arises the idea that after the percolation threshold is reached; further increase in NP amount probably causes aggregation, which ends up in the creation of multi directional conductive paths. Then, after 2 wt $\%$ NP amount, the conductivity increases for 100:0 case while it hits bottom gradually for 0:100 case. Again bringing into mind the aggregation of GOs, but for CNTs the achievability of conductive paths despite the aggregates and better interaction with CFs. That is: Contrary to GOs, MWCNTs can still form adequate paths for electron flow with further increase in their amounts. This phenomenon seems to be confirmed by the fiber direction behaviors of hybrid nanofiller cases as can be seen in Figure 5 (b, c and d). It draws attention that the conductivities are unstable till $7 \mathrm{wt} \%$ NP amount. After this point, it increases for 80:20, and decreases for 50:50 and 20:80 composites, again supporting the idea that MWCNTs cause positive effect on hybrid nanofiller cases while GOs cause negative when it comes to $\mathrm{CF}$ interaction. Another noticeable behavior seen in Figure 5 is that almost the same curve shapes occur for transverse and thickness directions in each 100:0, 80:20, 50:50, 20:80, and 0:100 composite specimen: e.g. take Figure 5 (a); transverse and thickness conductivity curves almost follow the same shape. The reason to this is probably the NPs cause similar effect in transverse and thickness directions; i.e. dispersion of NPs in epoxy resin is similar in both directions of each composite type. Another remarkable point is that the conductivity curve shape for fiber direction does not seem similar to those of the other two directions; that is: interaction of NPs with CF can be effective for conductivities of all composites in the fiber direction. But, when these curves are carefully examined, a resemblance can be noticed between the three curves of 100:0 composite, which again can confirm the above idea that MWCNTs can form adequate paths for electron flow with further increase in their amounts (Figure 5(a)). This idea can also be supported by the fiber direction behavior of 80:20 composites as can be seen in Figure 5(b) where all three curves follow similar shape after $4 \mathrm{wt} \%$. Similar comment can be made even for 50:50 composites as well (Figure 5(c)). But, it seems not possible to draw such conclusions for GO dominant composites such as 20:80 and 0:100 cases; it can be seen from Figure 5( $\mathrm{d}$ and e) that the fiber direction conductivity curves have almost no sign of similarity with the curves of other two directions. Moreover, the conductivity decreases after $7 \mathrm{wt} \%$ for 20:80, and after $2 \mathrm{wt} \%$ for 0:100 composites. This again can confirm that the more the GO amount, the more the formation of aggregates. And the more the MWCNT amount, the more the multi electron directions and the better the conductive paths and interaction with CFs, which is similar to another finding [15].

The conductivity ranges of all composites were also tabulated regardless of NP composition, but as a function of NP amount (Table 2). Here, a comparison with the literature was made as well: For $0.5 \mathrm{wt} \% \mathrm{NP}$ amount about 14 to 231 , for $1 \mathrm{wt} \% 3969$ to 9923 , and for comparison with a $3 \mathrm{wt} \%$ study [18] up to 2 folds conductivity values was achieved in thickness direction when compared to previous works. The increase ranges achieved in this study compared to that of neat composite values are 1.7-5.8, 122217, and 15-34 folds in fiber, transverse, and thickness directions, respectively. The reasons for these great increases when compared to both the neat composites and the literature can be homogeneous dispersion of NPs and also MWCNT-GO compositions within themselves, and functional groups occurring on GO surfaces as a result of oxidation. Additionally, when compared to literature, a small scale composite production was realized in this study, which could probably cause better dispersion and less material flaws.

Table 2. Conductivity ranges of composites and comparison with literature

\begin{tabular}{ccccc}
\hline $\begin{array}{c}\text { NP amount } \\
(\mathbf{w t} \%)\end{array}$ & $\begin{array}{c}\text { Fiber direction } \\
(\mathbf{S} / \mathbf{m m})\end{array}$ & $\begin{array}{c}\text { Transverse direction } \\
(\mathbf{S} / \mathbf{m m})\end{array}$ & $\begin{array}{c}\text { Thickness direction } \\
(\mathbf{S} / \mathbf{m m})\end{array}$ & Reference \\
\hline & 0.95 & 0.0023 & $74 \times 10^{-5}$ & $\begin{array}{c}\text { This study } \\
{[17]}\end{array}$ \\
0 & 6.2 & 0.0007 & $15 \times 10^{-6}$ & {$[16]$} \\
& - & - & $7.1 \times 10^{-6}$ & {$[18]$} \\
& & & 0.002 & {$[19]$} \\
\hline & & $0.6 \times 10^{-7}$ & This study \\
0.5 & $0.89-2.72$ & 0.0018 & $0.0030-0.025$ & 0.4 wt\% DWCNT [17] \\
& 6.3 & - & 0.000108 & 0.4 wt\% DWCNT [16] \\
\hline & - & $0.09-0.35$ & $0.0052-0.013$ & This study \\
1 & $1.21-1.65$ & - & $13.1 \times 10^{-7}$ & 1 wt\% G [19] \\
\hline 2 & - & $0.04-0.29$ & $0.0019-0.015$ & This study \\
& $0.58-1.85$ & & 0.007 & 3 wt\% G [18] \\
\hline 4 & $1.22-2.45$ & $0.11-0.28$ & $0.0050-0.011$ & This study \\
7 & $1.06-4.00$ & $0.05-0.38$ & $0.0028-0.022$ & This study \\
10 & $1.07-5.23$ & $0.07-0.30$ & $0.0028-0.014$ & This study \\
15 & $1.12-5.47$ & $0.08-0.44$ & $0.0049-0.014$ & This study \\
\hline
\end{tabular}




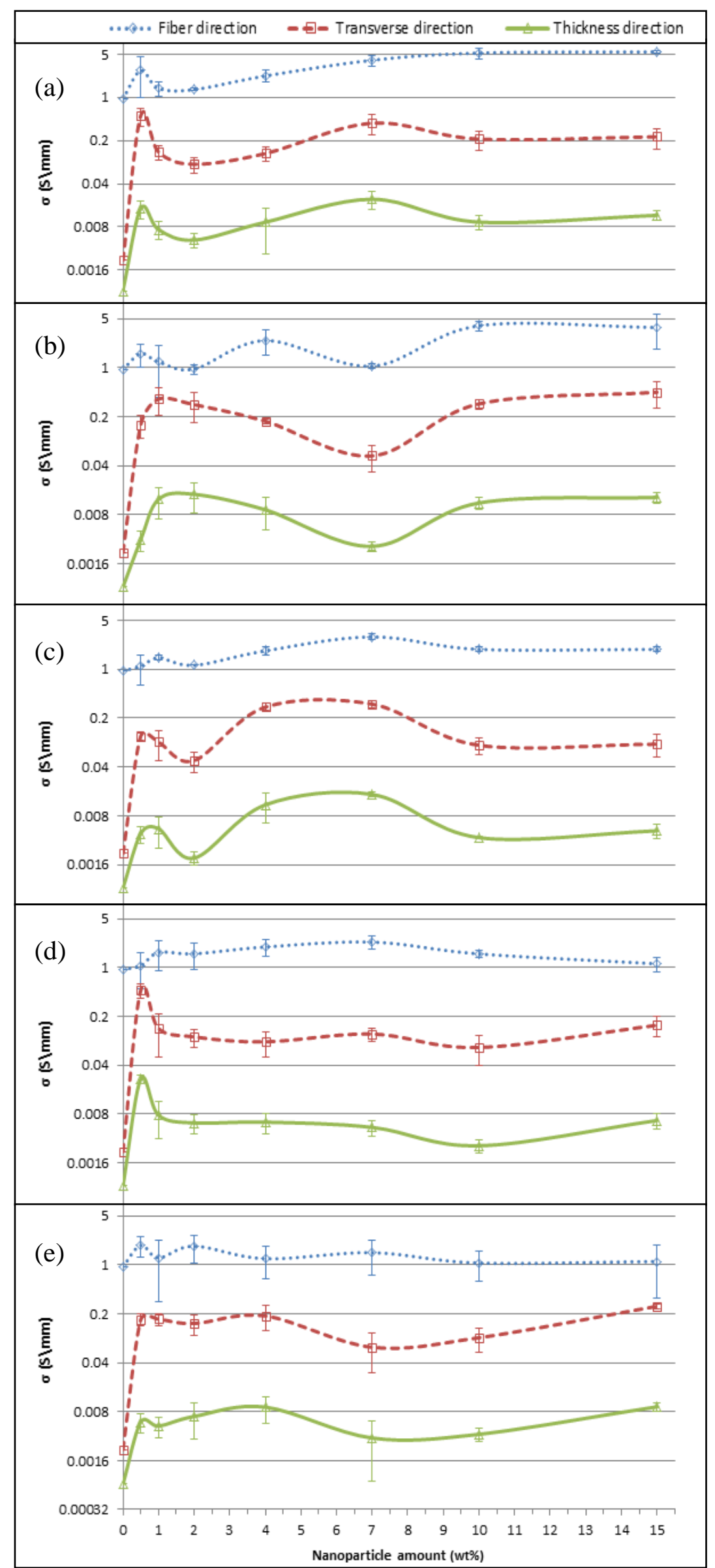

Figure 5. Electrical conductivity of composites with MWCNT:GO ratios (a) 100:0, (b) 80:20, (c) 50:50, (d) 20:80, and (e) 0:100 
Figure 6 also shows that the conductivities in fiber direction decrease as the NP type changes from MWCNT to GO for especially high NP loading ratios and even slightly for 0.5 wt $\%$. But, for NP amounts of 1 and $2 \mathrm{wt} \%$, this is not much apparent. One can also conclude from the graph that the more the NP amount, the higher the conductivity values in fiber direction. Similarly, in transverse direction, conductivities decrease as the NP type changes from MWCNT to GO, but except for 1, 2, and $4 \mathrm{wt} \%$ this time. Also, $0.5 \mathrm{wt} \% \mathrm{NP}$ loading seems quite adequate for achieving high conductivities in transverse direction (Figure 7). These conductivity decreases recorded in general with the change in NP type from MWCNT to GO can be due to the problems regarding the dispersion of high graphene contents [15]. This was observed by Han et al. whose study revealed that Gs were folded and overlapped resulting in large areas within epoxy resin while MWCNTs showed uniform dispersion. They also found higher conductivity value for the case of CNT than that of $\mathrm{G}$ incorporation. Additionally, when acetone suspensions of Gs and MWCNTs were left to precipitate, it was seen that the sediments of Gs showed the most packing density while CNTs were not seen to be highly packed. These were explained as a result of the plate-like structure of Gs and the tube-like structure of CNTs. Gs' structure allowed precipitation without leaving internal voids while MWCNTs' structure caused sliding between the nanotubes leaving internal empty spaces [23]. In case of thickness direction, unlike the other two directions, conductivities do not change with respect to NP type except for high NP loadings (Figure 8). Relatively low increase in fiber direction conductivities when compared to other two directions is obvious (Figure 6). And, a high jump is remarkably seen in transverse direction conductivity (Figure 7). Although not as much, again a clear increase is visible in thickness direction as well (Figure 8).

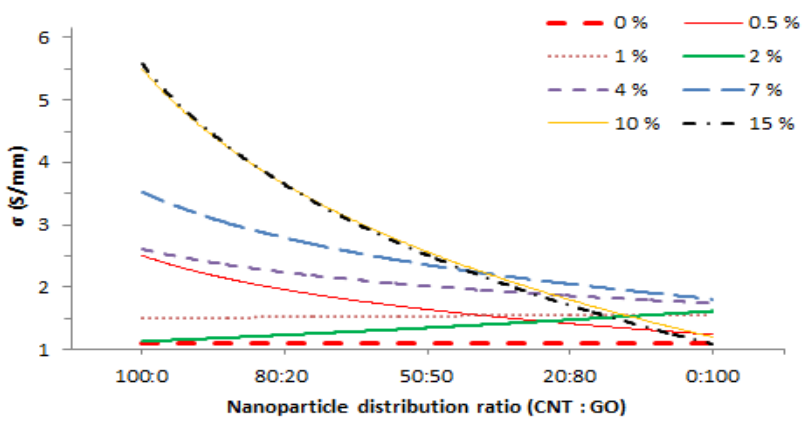

Figure 6. Electrical conductivity of composites in fiber direction with respect to CNP composition

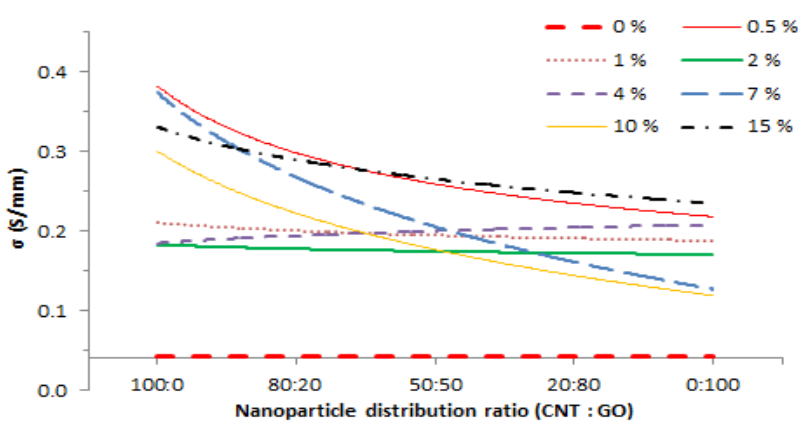

Figure 7. Electrical conductivity of composites in transverse direction with respect to CNP composition

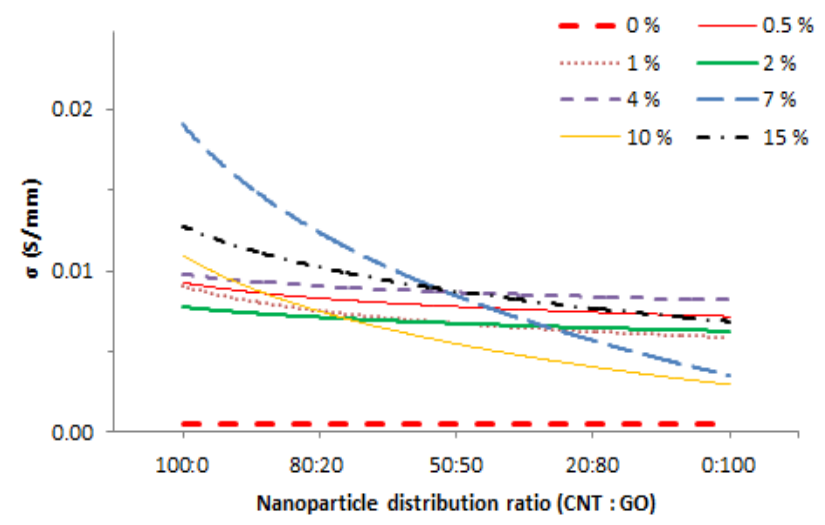

Figure 8. Electrical conductivity of composites in thickness direction with respect to CNP composition

\subsection{ILSS of composites}

ILSS values, as can be seen in Figure 9, reached a maximum of about $39.5 \mathrm{MPa}$ after NP incorporation, which is $87 \%$ more than that of the neat CF/epoxy composite given as 21.1 MPa [20]. When compared with the literature, this increase is an excellent improvement level: Some ILSS value increments from previous works are 19\% [18], 58\% [20], 40\% [22], and 90\% [28]. High values were recorded for especially low NP loadings such as 0.5 and $1 \mathrm{wt} \%$ for all NP composition types. All NP compositions improved the ILSS of CF/epoxy composites according to the neat one except the 0:100 case. In general, ILSS values decreased with the increase in NP amount (Figure 10), which is in accordance with a previous work result for $1.5 \mathrm{wt} \%$ [22]. This again suggests that the more the NP amount, the more they are aggregated. This can decrease mechanical property values as NP aggregates will act as stress concentrators or crack initiators inside the composite structure. Figure 10 clearly shows that ILSS values decrease also as the NP type changes from MWCNT to GO, which supports the idea that GOs are more susceptible to aggregation than MWCNTs. A synergy between MWCNTs and GOs can be mentioned in 50:50 and 20:80 cases for 0.5 wt $\%$ CNP amount, and also in 80:20 CNP case for $1 \mathrm{wt} \%$, and slightly in 50:50 case for $4 \mathrm{wt} \%$. It is again seen here that high CNP loadings cause decrease in ILSS values.

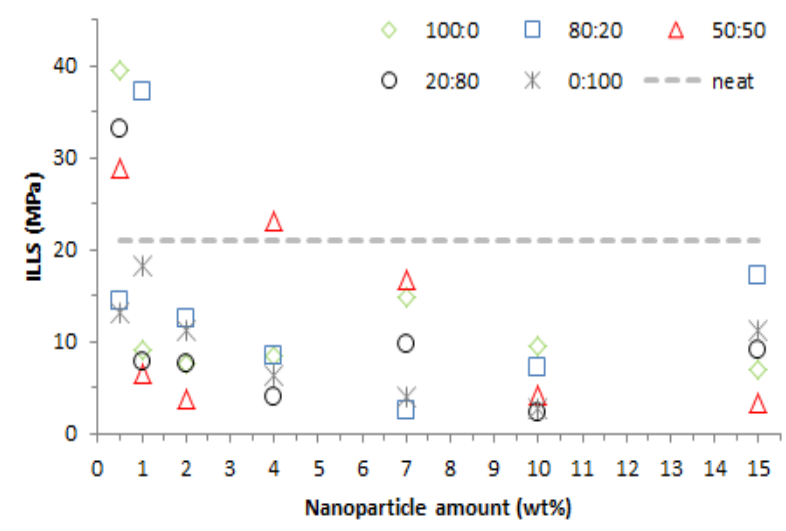

Figure 9. ILSS values of composites with respect to CNP fill ratio 


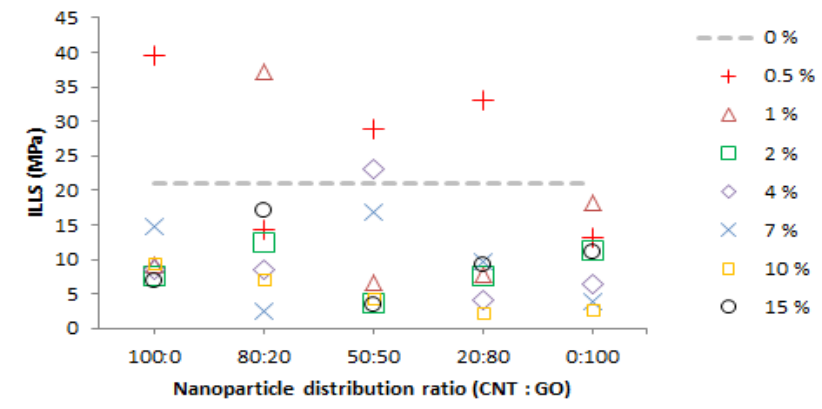

Figure 10. ILSS values of composites with respect to CNP composition

\subsection{Morphology of nanoparticles}

SEM-EDS analyses results were given for 100:0, 50:50, and 0:100 CNP compositions in Figure 11. First row are the captured images of CNPs at 100,000 x magnification level. Here, $100 \%$ CNTs show a well-known wormlike structure (Figure 11(a). On the other hand, 50:50 CNP specimen images indicate that the GO NPs much more appear in aggregate forms distributed along the CNT worms (Figure 11(b)), which was also stated by other researchers [26]. Although similar view was generally observed for $100 \%$ GOs, it was also achievable to capture images showing their layered structure as well (Figure 11(c)). EDS analyses confirmed increase in surface oxygen atomic percentage (at\%) of CNPs in the order 100:0 < 50:50<0:100 indicating that GOs dominate the oxygen content of the NP compositions (Figure 11(d, e and f)). Although oxygen functional groups, which are essential for interaction between CFs and epoxy resin, were found to be higher on GO surfaces, it seems that this mechanism was not much effective in this work. When the SEM images are correlated with the electrical and mechanical test results, dispersion and NP type seem to be much more decisive factors in CFR nano-epoxy prepreg composites. MWCNTs' cylindrical wormlike structure is probably more prone to aggregation when compared to GOs' nanoscale plate-like layered structure. Similar findings such as folding, overlapping, and densely packing of Gs caused probably by their plate-like structure were also stated [23]. There, it was also mentioned that MWCNTs showed more uniform dispersion in the matrix and were not highly packed in suspensions as they can slide between each other. This was again due to the tube-like structure of CNTs. This structural difference also can enable MWCNTs to cause bridging, which can prevent crack growth in the composite. Another important point is that MWCNTs' structure can let them interact more with CFs and have more contact surfaces [15, 28], which in turn can help develop more conductive paths in the CF/epoxy composite.

\section{CONCLUSION}

CFR epoxy prepreg composites with hybrid NP incorporation were successfully produced. NP amount was varied as $0.5,1,2,4,7,10$, and $15 \mathrm{wt} \%$. Besides, within these CNP percentages, MWCNT to GO ratio was also changed as 100:0, 80:20, 50:50, 20:80, and 0:100. Electrical and mechanical tests were conducted to investigate the effect of NP addition, but moreover the synergetic effects of hybrid nanofillers. Most of the composites showed a sudden increase at about $0.5 \mathrm{wt} \%$ especially for MWCNT dominant cases and between $0.5-1 \mathrm{wt} \%$ for GO dominant cases. Up to 5.8 (for 15wt\% and 100:0), 217 (for 0.5wt\% and 100:0), and 34 fold (for $0.5 \mathrm{wt} \%$ and 20:80) increases in

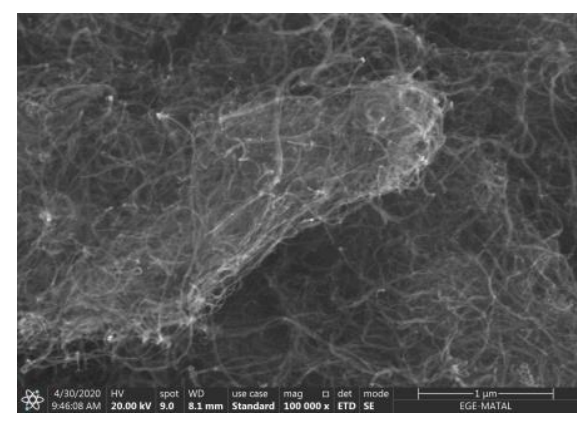

(a) 100:0

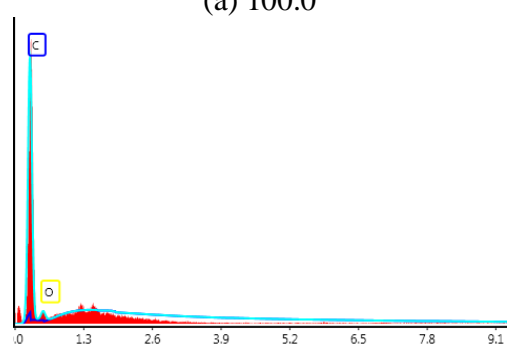

(d) 100:0 (C:O=92.59:7.41 at\%)

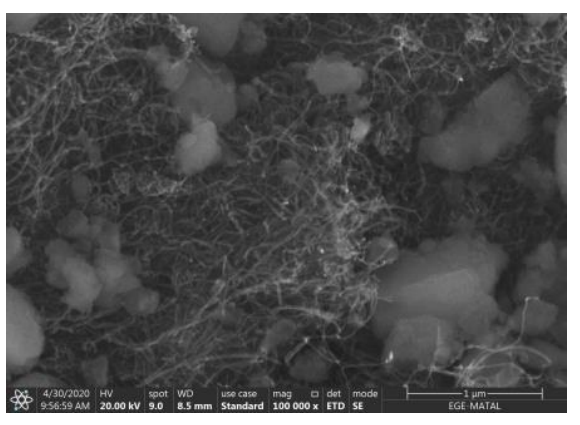

(b) $50: 50$

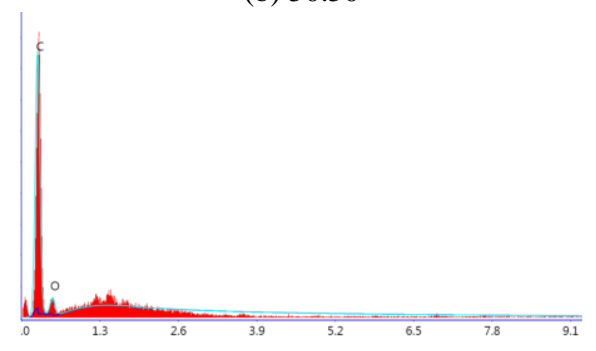

(e) $50: 50(\mathrm{C}: \mathrm{O}=87.84: 12.16$ at $\%)$

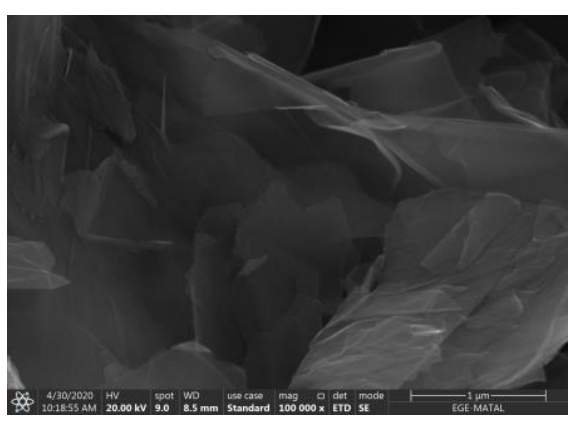

(c) $0: 100$

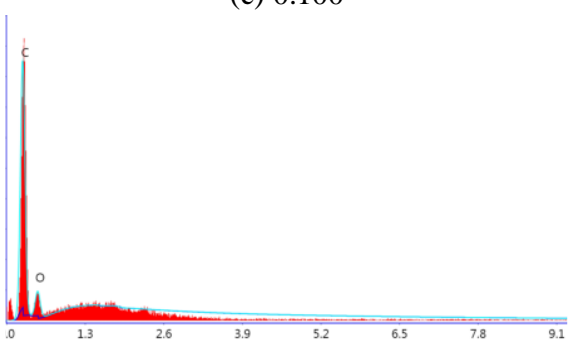

(f) $0: 100(\mathrm{C}: \mathrm{O}=83.62: 16.38$ at $\%)$

Figure 11. SEM-EDS analyses of CNPs 
electrical conductivity values in fiber, transverse, and thickness directions, respectively, were achieved when compared to that of the neat composite. Also, approximately $87 \%$ (for $0.5 \mathrm{wt} \%$ and 100:0) increase in ILSS value was achieved by CNP addition. All NP compositions improved ILSS of composites except the $0: 100$ one. Interpretations of the test results were confirmed by SEM and EDS analyses. Mechanical and electrical test results also revealed that the values decreased as the NP composition changed from MWCNT to GO. Therefore, it was decided that the oxygen functional groups on GO surfaces did not affect composite properties as much as MWCNT structure, which prevented its aggregation and improved its interaction with $\mathrm{CFs}$, thereby creating more conductive paths in the composite material, more bridging and less crack initiators or flaws.

\section{REFERENCES}

1. Tuakta C. 2005. Use of fiber reinforced polymer composite in bridge structures (Master's thesis). Massachusetts Institute of Technology, Civil and Environmental Engineering, Massachusetts, Boston.

2. Autar KK. 2006. Mechanics of Composite Materials. Boca Raton: Taylor \& Francis Group.

3. Sanjay KM. 2001. Composites Manufacturing: Materials, Product, and Process Engineering. CRC Press.

4. Smallman RE, Bishop RJ. 1999. Modern Physical Metallurgy and Materials Engineering. Oxford: Butterworth Heinemann.

5. Taherian R, Kausar A. 2018. Electrical Conductivity in PolymerBased Composites Experiments, Modelling, and Applications. Elsevier.

6. TS EN ISO 2076:2014; Tekstil- Yapay lifler - Grup isimleri (ISO 2076:2013). Ankara: Türk Standartları Enstitüsü.

7. Agarwal BD, Broutman LJ, Chandrashekhara K. 2006. Analysis and Performance of Fiber Composites. New Jersey: John Wiley \& Sons.

8. Goldstain A. 1997. Handbook of Nanophase Materials. New York: Marcel Dekker Inc.

9. Rao CNR, Müller A, Cheetham AK. 2005. The Chemistry of Nanomaterials Volume 1. Weinheim: WILEY-VCH Verlag GmbH \& Co. KgaA.

10. Miller JC, Serrato R, RepresasCardenas JM, Kundahl G. 2004. The Handbook of Nanotechnology. New Jersey: John Wiley \& Sons, Inc.

11. Liveri VT. 2006. Controlled Synthesis of Nanoparticles in Microheterogeneous Systems. USA: Springer.

12. Pérez J, Bax L, Escolano C. 2005. NRM Nanoroadmap Project: Roadmap Report on Nanoparticles. Willems \& van den Willenberg (W\&W): Spain.

13. Neto AH, Guinea F, Peres NMR. 2006. Drawing conclusions from graphene. Physic World, 19(11), 33-37.

14. Sharifzadeh M. 2006. Nanotechnology Sector Report, Cronus Capital Markets.

15. Ma PC, Siddiqui NA, Marom G, Kim JK. 2010. Dispersion and functionalization of carbon nanotubes for polymer-based nanocomposites. Composites Part A: Applied Science and Manufacturing 41(10), 1345 1367

16. Lonjon A, Demont P, Dantras E, Lacabanne C. 2012. Electrical conductivity improvement of aeronautical carbon fiber reinforced polyepoxy composites by insertion of carbon nanotubes. Journal of Non-Crystalline Solids 358(15), 1859-1862.

17. Sawi IE, Olivier PA, Demont P, Bougherara H. 2012. Processing and electrical characterization of a unidirectional CFRP composite filled with double walled carbon nanotubes. Composites Science and Technology 73, 19-26.

18. Qin W, Vautard F, Drzal LT, Yu J. 2015. Mechanical and electrical properties of carbon fiber composites with incorporation of graphene nanoplatelets at the fiber-matrix interphase. Composites: Part B 69, $335-340$.
The findings in the work suggest that further investigations on NP dispersion techniques, NP functionalization, incorporation of graphene and its oxides obtained by different methods, and other composite properties such as EMI shielding and additional mechanical properties can be considered as future work. Also, a lower NP loading range such as $0.1-1 \mathrm{wt} \%$ can be studied to determine the change in the percolation threshold of CNP incorporated carbon fiber reinforced epoxy composites.

\section{Acknowledgement}

The author(s) wish to thank Barış Oğuz GÜRSES for his support in conductivity measurements, Semih Kiral for his support in production, and TUBITAK (The Scientific and Technological Research Council of Turkey) for its 2211 Domestic Graduate Scholarship Program.

19. Imran KA, Shivakumar KN. 2019. Graphene-modified carbon/epoxy nanocomposites: Electrical, thermal and mechanical properties. Journal of Composite Materials 53(1), 93-106.

20. Acar V. 2013. Karbon iplik dolgulu termoset film kompozitlerde ara yüzey çalıșmaları (Master's thesis). Atatürk Üniversitesi, Erzurum.

21. Shekar KC, Prasad BA, Prasad NE. 2014. Interlaminar shear strength of multi-walled carbon nanotube and carbon fiber reinforced, epoxy matrix hybrid composite. Procedia Materials Science 6, 1336-1343.

22. Wang P-N ,Hsieh T-H,Chiang C-L, Shen M-Y. 2015. Synergetic effects of mechanical properties on graphene nanoplatelet and multiwalled carbon nanotube hybrids reinforced epoxy/carbon fiber composites. Journal of Nanomaterials Article ID 838032, 9 pages, DOI: $10.1155 / 2015 / 838032$.

23. Han S, Meng Q, Pan X, Liu T, Zhang S, Wang Y, Haridy S, Araby S. 2019. Synergistic effect of graphene and carbon nanotube on lap shear strength and electrical conductivity of epoxy adhesives. Journal of Applied Polymer Science 136(42), https://doi.org/10.1002/app.48056.

24. Yue L, Pircheraghi G, Monemian SA, Manas-Zloczower I. 2014 Epoxy composites with carbon nanotubes and graphene nanoplatelets - Dispersion and synergy effect. Carbon 78, 268-278.

25. Ghaleb ZA, Mariatti M, Ariff ZM. 2017. Synergy effects of graphene and multiwalled carbon nanotubes hybrid system on properties of epoxy nanocomposites. Journal of Reinforced Plastics and Composites 36(9), 685-695.

26. Yavari F, Chen L, Zandiatashbar A, Yu Z, Koratkar N. 2012. Synergy derived by combining graphene and carbon nanotubes as nanofillers in composites. Journal of Nanoscience and Nanotechnology 12(4), 3165-3169.

27. Qi Z, Tan Y, Zhang Z, Gao L, Zhang C, Tian J. 2018. Synergistic effect of functionalized graphene oxide and carbon nanotube hybrids on mechanical properties of epoxy composites. RSC Advances 8, 38689-38700

28. Qin W, Chen C, Zhou J, Meng J. 2020. Synergistic effects of graphene/carbon nanotubes hybrid coating on the interfacial and mechanical properties of fiber composites. Materials 13(1457), doi: $10.3390 / \mathrm{ma} 13061457$

29. Laachachi A, Vivet A, Nouet G, Doudou BB, Poilâne C, Chen J, Bo bai J, Ayachi M. 2008. A chemical method to graft carbon nanotubes onto a carbon fiber. Materials Letters, 62, 394-397.

30. Kumar KV, Safiulla M, Ahmed K. 2012. Influence of UTM testing speed on ILSS and flexural strength of fiber epoxy composites. International Journal of Advanced and Innovative Research ISSN: 2278-7844, 327-332.

31. Yu A, Ramesh P, Sun X, Bekyarova E, Itkis ME, Haddon, RC 2008. Enhanced thermal conductivity in a hybrid graphite nanoplatelet - carbon nanotube filler for epoxy composites. Advanced Materials 20(24), 4740-4744. 
